www.jmscr.igmpublication.org

Index Copernicus Value: 79.54

ISSN (e)-2347-176x ISSN (p) 2455-0450

crossref DOI: https://dx.doi.org/10.18535/jmscr/v7i5.42

Journal Of Medical Science And Clinical Research

IGM Publication

An official Publication of IGM Publication

\title{
Survey and inspection of household water storage containers to find out presence of mosquito larvae and study of socio behavioural factors leading to positive larval indices in urban households of Sagar city of Madhya Pradesh
}

\author{
Authors \\ Sunil K Guleri ${ }^{1}$, Dr Ram Kumar Panika ${ }^{2 *}$ \\ Department of Community Medicine, Bundelkhand Medical College Sagar, Madhya Pradesh, India \\ *Corresponding Author \\ Dr Ram Kumar Panika \\ Department of Community Medicine, Bundelkhand Medical College Sagar, Madhya Pradesh, India \\ Email: drramkumartandiya@gmail.com, Contact No.: 8435575804
}

\begin{abstract}
Rising episodes of outbreaks of dengue and chikungunya indicates flourishing of mosquitoes in household containers. mosquito can be controlled by source reduction, health education and community participation. The study was conducted to find out prevalence of larval positivity indices (house index (HI), container index $(C I)$, breteaue index (BI) and pupa index (PI)), and find out the factors leading to long time storage of water. This study was done in 5 randomly selected wards of the municipal corporation Sagar. 400 households were studied, selecting 80 houses from each ward randomly. Pretested structured questionnaire was used for interview with the head of family / adult member of the family. All the containers available and accessible in the households were inspected for presence of mosquito larvae and pupa were counted after staining with an stainer tied with a long stick. The data collected was analysed using SPSS software and chi square test was applied as test of significance. The results show HI, CI, BI and PI of 27.00, 11.19, 28.75 and 43.00 respectively. Large mason tanks, over head tanks and plastic water drum were the most common containers with larvae presence. Regular assured water supply by public water supply system will discourage the people to store water unnecessarily. The water containers should be kept covered properly and water should be changed at least once in a five days period. Large mason tanks should be covered and water may be pumped out to make them empty.
\end{abstract}

Keywords: mosquito larvae indices, Household containers.

\section{Introduction}

House hold water storage containers are the breeding sites of Aedes aegypti mosquitoes which occupies a very special position in preventive medicine. It is the first proved vector of a virus disease- yellow fever. It is also the cause of dengue fever and chikungunya. Aedes aegypti is widely distributed in India and breeds in artificial accumulations of water in and around human dwellings, such as water found in discarded tins, broken bottles, fire buckets, flower pots, coconut shells, earthen pots, and the like. ${ }^{[1]}$

It is well adapted for breeding in small collections of water. The cigar shaped eggs are laid singly on damp surfaces on stagnant water. During the pre monsoon period the breeding is restricted to water 
collections meant for domestic use. They may breed in tree holes if these are within about $20 \mathrm{~m}$ of houses. The eggs after maturing may remain viable for considerable periods even after dryingup of the breeding sites, and hatch out during rains. Such surviving eggs rapidly build up the adult mosquito population when rains come. Their capacity to complete life cycle indoors enables them to breed in urban areas throughout the year, irrespective of the prevailing external climate. Communities or sections of the cities with water scarcity, which leads to water storage practices, are mostly harassed by Aedes aegypti. ${ }^{[2]}$

These are sometimes called tiger mosquitoes because of the stripes on their legs. ${ }^{[3]} \mathrm{A}$. aegypti, is an efficient vector, the females bite man during the day. Low density of 3 per 10 man hours catch is enough to carry on the epidemic. ${ }^{[4]}$ Surveillance on Aedes. aegypti density is important in determining factors related to dengue transmission, in order to prioritize areas and seasons for vector control. ${ }^{[5]}$ Aedes mosquito can be controlled by vigorous anti-adult and antilarval measures. The long-term policy should be based on organized "source reduction" methods (e.g., elimination of breeding places) supported by health education aimed at securing community participation. ${ }^{[6]}$ The study was conducted with the objective of finding out prevalence of larval positivity (House index, Breteau index and container index) in water containers of urban households, find out the factors leading to long time (more than a week) storage of water and motivate people to practice the activities to eliminate the domestic and peri-domestic breeding sites .

The larval survey data was calculated and analyzed in terms of different larval survey techniques like House Index (HI), Container Index (CI), Breteau Index (BI), Pupal Index (PI), Pupae Per Container Index (PCI) and Pupae Per Positive Container Index (PPCI) according to various methods (WHO, 2003; Service, 1976). ${ }^{[7]}$

The calculation of larval indices is based on the following mathematical formulae:
1. House Index $(\mathrm{HI})=$ Number of houses infested/Total number of houses inspected multiplied by 100 .

2. Container Index $(\mathrm{CI})=$ Number of positive containers infested/Total number of containers inspected multiplied by 100 .

3. Breteau Index $(B I)=$ Number of positive containers/ Total number of houses inspected multiplied by 100 .

4. Pupal Index (PI) = Number of pupae collected/Total number of houses inspected multiplied by 100 .

\section{Material \& Methods}

This is a cross sectional survey conducted in municipal carporation sagar during post mansoon season. Survey was conducted in 400 houses of five randomly selected wards. 80 households from each ward were also selected using simple random sampling. There are 52833 households as registered in district census handbook of sagar 2011 out of which desired sample size was calculated to be $382^{[8]}$

Sample size: 400 (required sample size is 382 i. e. where the prevalence (p) was taken 50\% (50\% when proportion/prevalence is unknown) using openepi software. The required precision of the estimate (d) set as 5\% confidence level $95 \%$.)

○ Formula for sample size calculator: ${ }^{[9]}$

$$
s s=Z^{2}(p)(1-p) / c^{2}
$$

Sample size $=$ ss $/(1+$ ss $/$ POP $)$

Correction for finite population

Here $\mathrm{Z}=\mathrm{Z}$ value (e.g. 1.96 for $95 \%$ confidence level)

$\mathrm{p}=$ percentage picking a choice, expressed as decimal

(.5 used for sample size needed)

$\mathrm{c}=$ confidence interval (error), expressed as decimal $=0.05$

Sampling method: simple random sampling, 05 $(10 \%)$ wards were selected from the list of 49 wards of sagar municipal carporation and 
outgrowth. The selected wards were ambedkar ward (48), tili ward (46), shiwaji ward (05), bhojraj ward (47) and kakaganj ward (44). The separate ward wise population and number of households were assessed through the website. ${ }^{[10]}$ From each ward 80 households were selected for study from different streets of the wards.

Data collection and analysis: the research team went to survey in households of randomly selected wards. The head of the family (if not present wife/ adult son or daughter) was interviewed with a pretested structured questionnaire and the responses were recorded. After interview the team inspected all the containers of water storage available, the fridge tray, the cooler tank, mason tank, roof top water tank and any other suspected container storing residual rainy water. The presence of mosquito larvae was ensured by observing in good light (search light torch). The findings were recorded by the team and containers with larvae were emptied stat. The family members were asked to empty and dry all their water storage containers once a week and always keep the stored water covered. The collected data was entered into excel spread sheets and analysed using SPSS software version 20.

\section{Results}

400 households from five different wards of municipal area of sagar were surveyed. Among the interviewed persons $366(91.5 \%)$ were males and $34(9.5 \%)$ were females. The average age of respondents was 50 years $(50.20 \pm 12.7$ years $)$ with range of 63 years (21-84 years). The socioeconomic status of households was calculated using modified B G Prasad scale, taking AI consumer price index November 2018 as 302. ${ }^{[10,11]}$ Most of the households were in lower middle class $(28.2 \%)$. Table 1

Out of total 400 house surveyed in 5 different wards of the municipal area $108(27 \%)$ were having presence of mosquito larva in one or other container of water, refrigerators tray and or cooler tanks. Among all the team made active search of 1027 water containers in 400 houses. Out of this
115 containers had larvae. The study team tried to collect the entire pupa present in different containers but many large sized mason water tanks had lot of water, and it was not possible to collect and count pupa. Table 2 The different indices of mosquito larval indices are presented in table 3. The overall indices HI, CI, BI and PI were $27.00,11.19,28.75$ and 43.00 respectively. Table 3

Among the total containers (1027) examined for presence of mosquito larvae, only 115 (11.19\%) were positive. Large mason tanks, over head tanks and plastic water drum were the most common containers with larvae presence. Nearly all (36/38) mason water tanks remain uncovered. Table 4 The larvae positivity was more common in open containers then closed or covered containers and the difference was significant (Chi square value 253.237, $\mathrm{df}=1, \mathrm{p}=<0.0001)$.table 5

The different factors responsible for collection of water for larger duration are presented in table 4 . The most important factor responsible for large collection of water in house hold containers was the irregular and uncertain supply no public water supply system. Once the water is collected in large containers / tanks , many households didn't emptied/ changed water for more than 5 days because either they don't know that it may lead to breeding of mosquitoes(330/400) in it or the water remain unused (44/400). Few (140/400) households found it difficult to empty or change water of mason tanks because of its large size and tank dug underground. Cooler tank (77/400) water remains unchanged for many days and got refilled regularly because it was not accessible due to its position being kept outside windows. Nearly all households (378/400) were unaware of emptying refrigerator tray. Table 6 
Table 1: socioeconomic status of the households

\begin{tabular}{|l|c|c|c|}
\hline Socioeconomic status & $\begin{array}{c}\text { Per capita } \\
\text { monthly income }\end{array}$ & $\begin{array}{c}\text { Number of } \\
\text { house holds }\end{array}$ & Percentage \\
\hline Upper Class & Rs $\geq$ Rs. 6893 & 68 & $17.0 \%$ \\
\hline Upper Middle Class & Rs. 3447 -6892 & 72 & $18.0 \%$ \\
\hline Middle Class & Rs . 2068-3446 & 66 & $16.5 \%$ \\
\hline Lower middle Class & Rs. 1034-2067 & $\mathbf{1 1 3}$ & $\mathbf{2 8 . 2 \%}$ \\
\hline Lower class & Rs. $\leq 1034$ & 81 & $20.3 \%$ \\
\hline Total & & $\mathbf{4 0 0}$ & $\mathbf{1 0 0 \%}$ \\
\hline
\end{tabular}

Table 2: Distribution of households according to presence of mosquito larvae and or pupa in the water containers

\begin{tabular}{|c|l|c|c|c|c|c|}
\hline S. No & Location & $\begin{array}{c}\text { Total } \\
\text { houses }\end{array}$ & $\begin{array}{c}\text { Positive } \\
\text { houses }\end{array}$ & $\begin{array}{c}\text { Total } \\
\text { containers }\end{array}$ & $\begin{array}{c}\text { Positive } \\
\text { containers }\end{array}$ & $\begin{array}{c}\text { Pupa } \\
\text { Presence\# }\end{array}$ \\
\hline 1. & Ambedkar ward (48), and & 80 & 25 & 191 & 25 & 35 \\
\hline 2. & Bhojraj ward (47) & 80 & 31 & 211 & 34 & 71 \\
\hline 3. & Kakaganj ward (44). & 80 & 15 & 164 & 16 & 00 \\
\hline 4. & Shiwaji ward (05), & 80 & 16 & 224 & 18 & 43 \\
\hline 5. & Tili ward(46), & 80 & 21 & 237 & 22 & 23 \\
\hline 6. & Total & 400 & 108 & 1027 & 115 & 172 \\
& & $(100 \%)$ & $(27 \%)$ & $(100 \%)$ & $(11.19 \%)$ & \\
\hline
\end{tabular}

\#The presence of PUPA and their no. In small and number of pupa present in large mason water accessible water containers. It excludes the tanks and containers difficult to get access.

Table 3: Mosquito larval indices in different wards of municipal area

\begin{tabular}{|l|l|c|c|c|c|}
\hline S.no & Location & HI & CI & BI & PI \\
\hline 1 & Ambedkar ward (48), and & 31.25 & 13.08 & 31.25 & 43.75 \\
\hline 2 & Bhojraj ward (47) & 38.75 & 16.11 & 42.50 & 88.75 \\
\hline 3 & Kakaganj ward (44). & 18.75 & 9.75 & 20.00 & 00 \\
\hline 4 & Shiwaji ward (05), & 20.00 & 8.03 & 22.50 & 53.75 \\
\hline 5 & Tili ward(46), & 26.75 & 9.28 & 2.50 & 28.75 \\
\hline & Total & 27.00 & 11.19 & 28.75 & 43.00 \\
\hline
\end{tabular}

Table 4: Distribution of containers positive for mosquito larvae.

\begin{tabular}{|r|l|c|c|c|c|c|}
\hline S. No. & Type of container & \multicolumn{2}{|c|}{$\begin{array}{c}\text { Opened or not } \\
\text { covered properly }\end{array}$} & \multicolumn{2}{c|}{ Covered properly } & Total \\
\hline & & Positive & Negative & Positive & Negative & \\
\hline 1$)$ & Over head tanks & 12 & 7 & 5 & 246 & 270 \\
\hline 2) & Cylindrical concrete tank & 8 & 57 & 14 & 253 & 332 \\
\hline 3$)$ & Large bucket & 2 & 3 & 0 & 18 & 23 \\
\hline 4$)$ & Plastic drum & 11 & 15 & 6 & 267 & 299 \\
\hline 5$)$ & Houz/ naad & 9 & 7 & 3 & 6 & 25 \\
\hline 6$)$ & Large mason tanks & 36 & 0 & 1 & 1 & 38 \\
\hline 7$)$ & $\begin{array}{l}\text { Fixed ground } \\
\text { underground water tank }\end{array}$ & 5 & 15 & 3 & 17 & \\
\hline 8$)$ & Total & 83 & 104 & 32 & 808 & 1027 \\
\hline
\end{tabular}

Table 5: 2x2 Table to compare covered and uncovered containers positive for mosquito larvae

\begin{tabular}{|l|c|c|c|}
\hline Containers & Positive & Negative & Total \\
\hline Open & 83 & 104 & 187 \\
\hline Closed & 32 & 808 & 840 \\
\hline Total & 115 & 912 & 1027 \\
\hline
\end{tabular}

Chi square value 253.237, $\mathrm{df}=1, \mathrm{p}=<0.0001$ 
Table 6: Factors responsible for artificial collections of water for more than 5 days

\begin{tabular}{|c|c|c|c|c|}
\hline S. No & Reason & $\begin{array}{r}\text { Yes (no. Of } \\
\text { households ) }\end{array}$ & $\begin{array}{l}\text { No. (no. Of } \\
\text { households) }\end{array}$ & Total \\
\hline 1) & Irregular supply of water by public water supply & 274 & 136 & 400 \\
\hline 2) & $\begin{array}{l}\text { Fear of shortage of water, and to conserve water for } \\
\text { emergency }\end{array}$ & 123 & 277 & 400 \\
\hline 3) & Don't know the need to empty container /change water & 330 & 70 & 400 \\
\hline 4) & Difficulty to empty large mason tanks at ground level & 140 & 260 & 400 \\
\hline 5) & Stored water often remains unused for more than a week. & 44 & 366 & 400 \\
\hline 6) & $\begin{array}{l}\text { The cooler tanks kept at height on windows remain } \\
\text { inaccessible to clean. }\end{array}$ & 77 & 333 & 400 \\
\hline 7) & Not aware to empty the water collected on refrigerator tray. & 378 & 22 & 400 \\
\hline
\end{tabular}

\section{Discussion}

Total of 400 houses were surveyed from 05 residential wards (Table 1) and 108 houses were had positive breeding sources for mosquitoes. The study examined only artificial breeding sources. Out of 1027 containers screened 115 containers were found to positive for mosquito larvae and breeding (Table 2). On the basis of positive houses and positive containers observed, the various larval indices were calculated. The data can be used to determine the possibility of mosquito borne illnesses like malaria and dengue and their outbreaks. In our study the HI, CI, BI, and PI varied from 18.75 - 38.75, 8.03-16.11, $2.50-42.50$ and $00-88.75$ respectively (Table $3)$. These indices were quietly higher from an study by Bhat MA et al (2014) in Tamilnadu where HI, CI, BI, and PI varied from $5.00-30.00$, $0.87-6.43, \quad 5.00-30.00$ and $00-86.67$ respectively ${ }^{[13]}$. The pupal index (PI) like the pupae/house in our study remains incomplete as it didn't included inaccessible containers to count up pupae present. Many studies also mention pupal productivity fluctuations like American studies (Burkot et al., 2007). ${ }^{[14]}$ Among various larval indices, house index and container index provides information on the extent of breeding and intensity of breeding respectively. The breteau index combines the information of both the houses and containers, and thus it is an excellent risk indicator of dengue outbreaks (Tun-Lin et al., 1996). ${ }^{[15]}$ Pupal indices are important to know the intensity of transmission and were considered the better and alternate indicator for adult mosquito abundance (Wai et al., 2012). ${ }^{[16]}$
The major breeding sources (Table 4) observed were large mason tanks $(37 / 115,32.17 \%)$ followed by Plastic drums 17/115 (14.78\%), over head 17/115 (14.78\%), and others. Bhat MA et al found Cement tanks 17 (4.79\%) followed by Plastic drums $13(4.36 \%)$, Tyres 2 (2.56\%), Grinding stones $3(2.29 \%)$, as major breeding sites. ${ }^{[13]}$ Similar studies have also been conducted in Tiruchirappalli (Rajesh et al., 2013) and Virudhunagar (Wilson et al., 2014) districts of Tamil Nadu, India. ${ }^{[17],[18]}$

Among the factors responsible for water collection for larger time inadequate, irregular supply of water by municipal carporation was the most important. Once water containers were filled, households failed to empty it due to unawareness that it is a breeding site for mosquito and or water remains unused. Also the inaccessibility and difficulty to clean air coolers, and large mason tanks also lead to breeding of mosquitoes.

\section{Conclusion}

The study found high mosquito larvae indices in the municipal corporation areas of sagar. The mosquitoes and illness caused by mosquito bites like dengue malaria are causing large scale morbidity and health expenditure to households. Regular assured water supply by public water supply system will discourage the people to store water unnecessarily. The water containers should be kept covered properly and water should be changed at least once in a five days period. Large mason tanks should be covered and water may be pumped out to make them empty. Window air coolers can be modified so that mosquito breeding 
can be prevented. National centre for disease control, national institute of communicable diseases (NICD) has developed special coolers which have advantage that no weekly cleaning of the water tank is required, no chemical larvicide is required to kill mosquito larvae and it can be conveniently installed in high rise buildings. ${ }^{[19]}$ But this noble item has limited supply and market dealers. This should be promoted for sale to general public. People should be made aware through mass media to prevent household breeding of mosquitoes so as to prevent rapid outbreaks of dengue and chikungunya like diseases.

\section{Source of support: nil}

\section{References}

1. K Park .Parks textbook of preventive and social medicine, 23rd edition, Jabalpur: Bhanot Publishers; 2015.p 771

2. Col Rajvir Bhalawar. Textbook of Community Medicine, $2^{\text {nd }}$ Edition: Wolters Kluwer India Private Limited; 2017. P 694)

3. Mahajan \& Gupta. Textbook of Preventive and Social Medicine , $4^{\text {th }}$ Edition, New Delhi: Jaypee brothers Medical publishers (p) limited;2013.p 112,329

4. Mahajan \& Gupta.Textbook of Preventive and Social Medicine , $4^{\text {th }}$ Edition, New Delhi: Jaypee brothers Medical publishers (p) limited;2013.p 329

5. https://www.who.int/denguecontrol/monit oring/vector_surveillance/en accessed on 12 october 2018.

6. K Park .Parks textbook of preventive and social medicine, 23rd edition, Jabalpur: Bhanot Publishers; 2015.p 283

7. World Health Organization .2003. Guidelines for Dengue surveillance and mosquito control (2 Ed.), Regional Office of the Western Pacific, Manila.

8. District census handbook Sagar 2011, Directorate of Census Operations Madhya Pradesh.

Available http://censusindia.gov.in/2011census/dchb/ 2310_PART_B_DCHB_SAGAR.pdf.

Assessed on 21 October 2018.

9. Creative research system survey software. Available at: http://www.surveysystem.com/samplesize-formula.htm. Assessed on 26 October 2018.

10. Sagar Municipal Corporation And Out Growth. Available at: https://indikosh.com/city/482683/sagar. Assessed on 26 October 2018.

11. Index numbers. Available at: labourbureaunew.gov.in/LBO_indnum.ht m. Assessed on 3rd December 2018.

12. Gupta P, Kumar P, Aggarwal OP. The Journal of Communicable Diseases, 1998, 30(2):107-112.

13. Bhat MA Krishnamoorthy K. Entomological investigation and distribution of Aedes mosquitoes in Tirunelveli, Tamil Nadu, India. Int. J. Curr. Microbiol. App.Sci (2014) 3(10) 253-260

14. Burkot T. R., Handzel T., Schmaedick M.A., Tufa J., Roberts J.M., and Graves P.M. 2007. Productivity of natural and artificial containers for Aedes polynesiensis and Aedes aegypti in four American Samoan villages. Med Vet Entomol. 21: 22-29.

15. Tun-Lin, W., B. H. Kay, Barne A., S. Forsyth, 1996. Critical examination of Aedes aegypti indices: correlations with abundance.Am J Med Hyg, 54(5): 543-547

16. Wai K.T., Arunachalam N., Tana S., Espino F., Kittayapong P., Abeyewickreme W., Dilini H., Petzold M. 2012. Estimating dengue vector abundance in the wet and dry season: implications for targeted vector control in urban and periurban Asia. Pathog Glob Health 106: 436445.

17. Rajesh K., Dhanasekaran D., Tyagi B.K. 2013. Survey of container breeding 
mosquito larvae (Dengue vector) in

Tiruchirappalli district, Tamil Nadu, India. J EntomolZool Stud.1:88-91.

18. Wilson J.J., Sevarkodiyone S.P., 2014. Breeding Preference Ratio of Dengue and Chikungunya Vectors in Certain Rural Villages of Virudhunagar District, Tamil Nadu, South India. World Appl Sci. J 30: 787-791

19. http://ncdc.gov.in>file616 accessed online on 12 October 2018. 